\title{
Emest Mandel
}

\section{¿Socialismo o neoliberalismo?.}

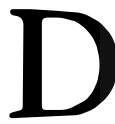

esde mediados de los setenta existe un ofensiva mundial del capital contra el trabajo y las masas trabajadoras del tercer mundo. Esta ofensiva expresa el agudo deterioro de la relación de fuerzas a expensas de los trabajadores a escala mundial. La ofensiva tiene condiciones objetivas y subjetivas.

Las condiciones objetivas son esencialmente el acelerado aumento del desempleo en los países imperialistas, de 10 hasta, al menos, 50 millones, si no más. Las estadísticas oficiales son todas estadísticas gubernamentales y éstas son una ficción. En los parses del tercer mundo, por lo menos, 500 millones están desempleados. Por primera vez, desde finales de la Segunda Guerra Mundial, el desempleo está elevándose masivamente también en las sociedades postcapitalistas burocratizadas.

Las condiciones subjetivas descansan esencialmente en el fracaso total del trabajo organizado y los movimientos de masas para resistir la ofensiva capitalista. En muchos países, estas organizaciones han sido la punta de lanza: Francia, Italia, España y Venezuela, sólo para mencionar algunos nombres, aunque hay una lista más completa. Esto ha hecho, sin duda, más difícil la resistencia a la ofensiva capitalista.

Dicho esto, no se debe subestimar el impacto concreto de las polf́ticas pseudo-liberales —en realidad neo-conservadoras - sobre el deserrollo mundial. Estas políticas, codificadas por el Fondo Monetario Internacional y el Banco Mundial, y simbolizadas por los gobiemos de la Thatcher y Reagan y sus muchos imitadores en los países del tercer mundo, han sido un inmitigable desastre.

Bajo el pretexto de dar prioridad a la estabilidad monetaria, la lucha contra la inflación y los presupuestos balanceados, los gastos sociales y de infraestructura han sido rápidamente recortados. Esto ha resultado en un incremento mundial de la desigualdad social, pobreza, enfermedades y amenazas al medio ambiente. 
Enfatizo en el cinismo de base de la ofensiva ideologica neoconservadora que acompaña a las políticas económicas conservadoras. Los neoconservadores afiman que quieren reducir drásticamente el gasto estatal. En realidad éste nunca ha sido tan alto como en los 80 y principios de los 90 bajo los neoconservadores.

Lo que realmente sucedio fue un desplazamiento de los gastos sociales y de infraestructura hacia los gastos militares, que para el período pueden ser estimados en tres trillones de d6lares, y hacia los subsidios hechos a las empresas. El salvamento de la bancarrota y la casi bancarrota de las instituciones financieras, como las asociaciones de ahorro y préstamo en los Estados Unidos, como también los gigantescos pagos de intereses de la ascendente deuda pública, pertenecen a esta categoría.

Los neoconservadores plantean que están por los derechos humanos pero en realidad, dadas las inevitables reacciones masivas en contra de estas políticas antisociales, los gobiernos neoconservadores crecientemente debilitan y atacan las libertades democráticas: la libertad sindical, el derecho al aborto, la libertad a la prensa, la libertad de trabajo y otras.

Ellos crean el clima apropiado para que las tendencias de la extrema derecha, el racismo, la xenofobia y el abierto neo- fascismo puedan emerger.

\section{Profundizando la pobreza del tercer mundo.}

El crecimiento mundial de la pobreza es desastroso. En el tercer mundo se ha convertido en una verdadera catástrofe. De acuerdo con las estadísticas de las naciones Unidas, más de 60 países con un total de más de 800 millones de habitantes, han sufrido una declinación absoluta en el producto interno percápita entre 1980 y 1990. En los más pobres de estos países, esta declinación está en el orden de 30 a $50 \%$. Para los estratos más pobres de las poblaciones de estos paŕses, la cifra oscila alrededor del $50 \%$. El producto doméstico perćpita en América Latina en 1950 era el $45 \%$ del obtenido en los parses imperialistas. En 1988, éste se desplom6 al 29.7\%.

Décadas de un modesto crecimiento en el bienestar público fueron borradas en el curso de unos pocos años. Lo que ésto significa concretamente puede ser ilustrado por el ejemplo de Perú. De acuerdo al New York Times, más del 60\% de la población peruana está desnutrida y el $79 \%$ vive bajo el nivel de pobreza, que está bastante arbitrariamente fijado en EUA $\$ 40$ al mes. Incluso los servidores públicos con título universitario ganan EUA $\$ 85$ al mes. Esto no es suficiente para pagar un mes del estacionamiento de carros en ese país.

En la práctica, un billón de gentes en el tiempo actual sufren de hambre en este planeta. Y esto sucede cuando existe una situacion de completa sobreproducción de alimentos. 
Los resultados son desastrosos no sólo desde un punto de vista social. También comienzan a tener resultados a nivel biológico. En el norte del Brasil ha aparecido una nueva raza de pigmeos, con un promedio de 35 centímetros menos que el promedio de los habitantes de Brasil. La clase burguesa gobernante y sus ideólogos caracterizan a esta gente como gente-ratas. Esta caracterización es deshumanizante, reminicente de los nazis y tiene siniestras implicaciones. Ya se sabe que se hace con las ratas.

Existe una amplia desnutrición debido al insuficiente consumo de vitaminas, minerales y proteinas animales. Mujeres y niños, especialmente, tienen estas deficiencias. Como resultado, los niños en el tercer mundo corren el riesgo 20 veces más grande de morir o sufrir enfermedades graves que los niños en los países imperialistas.

El destino de los niños simboliza el crecimiento del barbarismo en el tercer mundo. Este no es una cuestión de futuro; en el tercer mundo el barbarismo ya ha comenzado en escala gigante. De acuerdo a las cifras de UNICEF, cada año 16 millones de niños mueren de hambre o de enfermedades curables en el tercer mundo. Esto significa que cada 4 años hay un número de muertes de niños igual al de todos los muertos en la Segunda Guerra Mundial, Auschwitz, Hiroshima y la famina bengalí juntos. Cada 4 años hay una guerra mundial contra los niños. Allí está in nuce la realidad mundial del imperialismo y el capitalismo. Además, en el sur de Asia, el 20\% de las niñas bebés mueren antes de los cinco años de edad; $25 \%$ mueren antes de la edad de 15 años. El infanticidio de las niñas bebés está creciendo de año en año combinado con el uso masivo del trabajo infantil bajo condiciones de semi-esclavitud.

\section{Creciente desigualdad en países "avanzados"}

Los efectos desastrosos de las políticas económicas neo-conservadoras no están limitadas sólo a los países del tercer mundo o a las condiciones de vida de las masas de los habitantes de las sociedades post-capitalistas. Estos han comenzado a expandirse de manera más despaciosa, pero en forma real, hacia los países capitalistas también. En estos países, dependiendo de las fuentes que use, entre 55 y 70 millones de gentes viven bajo el nivel de pobreza. Una sociedad dual se está desarrollando con un número creciente de grupos sociales más o menos protegidos por la red de seguridad social: los desempleados, los trabajadores temporales, la gente viviendo de la beneficencia, las madres solteras que tienen que cuidar muchos niños, criminales desmoralizados son algunos de los elementos constituyentes de esa subclase.

Aquí hay otro ejemplo, muy triste e indignante, de lo que estoy diciendo. En el corazón de lo que ha sido historicamente el París revolucionario, donde cinco grandes revoluciones han comenzado, cada dł́a miles de inmigrantes, trabajado- 
res y artesanos casuales caminan sin rumbo esperando ser contratados. Algunas veces lo son, otras no.

Ellos no tienen protección social alguna, no tienen permiso de residencia. Compiten entre ellos mismos para trabajar por la comida que vale mucho más que lo que pueden ganar en sus propios parses.

La situación en los ghettos de Estados Unidos es típica de esta tendencia. El desempleo juvenil en los ghettos alcanza el $40 \%$ y la mayoría de estos jóvenes no tienen esperanza alguna de encontrar algún trabajo en el futuro. El mismo fenómeno se ha expandido de una manera más limitada hacia países europeos continentales y Gran Bretaña. La privatización acentúa estas tendencias.

Mientras los salarios reales en la actualidad declinan en EUA, el número de gente que tiene ingresos anuales brutos de un millón en dólares estables se ha elevado 60 veces. La gente que obtiene entre EUA $\$ 60,000$ y un millón se ha elevado de 78,000 a dos millones, pero no hay literalmente ni un sólo trabajador entre estos nuevos ricos.

\section{El rico se hace más rico}

Los efectos perversos de las políticas neoconservadoras en la economía mundial son bastante evidentes. El crecimiento de la pobreza del tercer mundo y la tercermundialización de los sectores de la población en los países imperialistas constituyen uno de los mayores frenos de cualquier expansión significativa de la economía mundial.

La deuda del tercer mundo a llevado a que el escandaloso y perverso desarollo del flujo neto de capitales desde el sur hacia el norte, con la parte más pobre de los países pobres subsidiando las partes más rìcas de los países ricos. Podríamos decir, en forma cínica, que eso no es nada nuevo, que eso ha sido siempre el capitalismo. De todas maneras, en esta dimensión y amplitud es al menos un nuevo fenómeno en el siglo veinte.

\section{Epidemias nuevas}

El más grande peligro de la tercer-mundialización del Sur, del Este y del Oeste es el despliegue de las típicas epidemias relacionadas con la pobreza, como el cólera y la tuberculosis que se presumía habían sido desterradas. También la ominosa amenaza del SIDA está de alguna manera relacionada con la pobreza. El ex-director del programa anti-Sida de la Organización Mundial de la Salud predice que al final del siglo, cien millones de personas estarán infectadas por el HIV, de los cuales el $25 \%$ caerá enfermo y morirá; el $85 \%$ de estas muertes ocurrirán en el tercer mundo. Esto no es el resultado de alguna especificidad cultural o étnica sino de deficiencias en la educación, prevención, programas de salud y saneamiento. Al mismo tiempo, 7 billones han sido gasta- 
dos en la batalla contra el SIDA desde el comienzo de la epidemia. Sólo el 3\% de esta suma ha sido gastada en el tercer mundo, donde vive el $85 \%$ de los infectados por el HIV. Obviamente es un suicidio pensar, incluso para la clase capitalista, que la expansión de la epidemia no alcanzará a los países capitalistas.

Bajo estas circunstancias, el llamado del Papa a limitar la lucha contra el SIDA con la auto-contención y la castidad de los individuos y al oponerse al uso de condones y de píldoras anticonceptivas es totalmente irresponsable. A la luz de los hechos, las políticas neoconservadoras de cortar los presupuestos de educación y salud en todas partes es irresponsable y suicida. Todos los efectos son económicamente y socialmente ominosos.

\section{La destructividad de la economía de mercado.}

En todos los departamentos universitarios en que se trabajan las políticas de desarrollo, en todas partes del mundo, es considerada una perogrullada que dentro de todas las inversiones productivas están las de educación, los programas de salud e infraestructura. Pero si usted cruza el corredor hacia los departamentos de economía llamados de finanzas públicas, oirá muy sorprendentemente, que un presupuesto balanceado es más importante que la inversión en educación, programas de salud e infraestructura y que hay que hacer recortes sin compasión en estos presupuestos con el fin de parar la inflación.

La humanidad está enfrentando amenazas atemorizantes para su sobrevivencia física: guerras biológicas, químicas y nucleares; guerras masivas tradicionales que podrían convertirse en guerras nucleares al bombardear estaciones de poder nuclear con armas convencionales; riesgos crecientes de destrucción del medio ambiente necesario para la vida humana tipificados como los efectos de la casa verde y el hoyo de ozono, destrucción de la selva tropical, desertificación de grandes partes de Africa y Asia y los efectos acumulativos de las catástrofes epidémicas.

Muchas personas han planteado el problema: ¿no es ya demasiado tarde? ¿No es inevitable el día final? ¿Podrá la humanidad sobrevivir los 50 años venideros? Nosotros creemos que la humanidad no está descartada. Creemos que la sobrevivencia puede tener éxito. Pensamos que no es pura intuición o ilusión. Es una creencia basada en datos científicos sólidos y en la dinámica actual de la investigación científica.

Sólo un ejemplo: existe ya una aproximación seria, concreta, para retroceder la desertificación del Africa; para irrigar el desierto, para convertirlo de nuevo en una región rica en la producción de alimentos como lo había sido hace 1,500 años atrás; para estimular a sus habitantes a aplicar técnicas agrícolas de conservación para desconectarlos del comercio de granos y orientarlos hacia los granos 
para alimentar a los africanos de una manera saludable. El efecto de un Sahara verde y boscoso en el clima mundial sería realmente sorprendente.

El problema a ser resuelto para derrotar el día final, en este caso, no es técnico, natural o cultural, es social. Para que esta solución sea aplicada se necesita sustituir el orden social basado en la avaricia, el deseo personal de acumular riquezas a pesar de todos los costos económicos y sociales y sustituir la pseudo-racionalidad de corto plazo por uno de racionalidad de largo plazo para determinar la conducta económica y social. Es necesario el poder en manos de fuerzas sociales que puedan prevenir que individuos, clases sociales y las principales fracciones de clase impongan su voluntad sobre la sociedad. El poder necesita estar en manos de la inmensa mayoría de los trabajadores deseosos de que prevalezca la solidaridad, la cooperación y la generosidad por medios democráticos por sobre el egoísmo de visión corta y la irresponsabilidad.

Quiero enfatizar que no es un proble de conciencia. El rico, los capitalistas, los poderosos, no son estúpidos. uueno, hay estúpidos entre ellos, pero muchos de ellos está conscientes perfectamente, por ejemplo, de los peligros ecológicos. Ellos tratan de considerarlos, los incluyen en su planificación y proyecciones económicas, pero bajo la presión de la competencia, bajo la presión de un sistema motivado por las ganancias, están forzados a actuar de tal forma que todas las amenazas permanezcan.

Algunos dicen que la ciencia y la tecnología han desarrollado una irresistible lógica propia y que el desarrollo incontrolado de la ciencia y la tocnología está llevando a la humanidad a un paso de la extinción y está amenazando con explotar nuestro planeta, pero ésta no es la forma correcta de ver las cosas. Esto es lo que se llamaría, en la filosofía marxista, el pensamiento reificado, la ciencia y la tecnología son presentadas como fuerzas divorciadas de los seres humanos quienes son las que las controlan. Pero esto es incorrecto.

\section{La lucha por la democracia de los trabajadores}

La ciencia y la tecnología no tienen poder independiente de los grupos sociales que las inventaron, las aplicaron y las unieron a sus intereses, tal como ellos las ven. El problema clave es sujetar a la ciencia y tecnología al control social consciente de los intereses establecidos democráticamente de la gran mayoría de los seres humanos, para liberarlos de la sumisión a intereses especiales que abusan de ellos a pesar de los intereses de largo plazo de la raza humana. Para este propósito, la organización y la estructura de la sociedad misma debe sujetarse democráticamente al control social consciente.

Desde esta perspectiva, el socialismo es la conquista de la libertad para el mayor número posible de la humanidad para que puedan decidir su propio destino en todos las esferas de la vida. Esto es verdad, en primer lugar, para todos los 
asalariados, mujeres y hombres, quienes están bajo la compulsión de vender su fuerza de trabajo y quienes representan hoy día una masa de gente mucho más grande de lo que eran en el pasado. Hay, ahora, más de un millón de asalariados. Aquellos que piden un gobierno de la minoría sobre esa libertad -libertad de los asalariados a decidir por sí mismos, en una forma democrática, qué prioridades aplicar a la producción y cómo producir y distribuir al menos las mayores cantidades de ésta- aquellos que afirman que esta libertad debe estar subordinada a las reglas del mercado, reglas de los ricos, reglas de los expertos, reglas de las iglesias, reglas del Estado o de los partidos, arrogantemente asumen la perfección de su conocimiento y de su sabiduría y subestiman la capacidad de las masas para igualarlos o para sobrepasarlos. Rechazamos estas afirmaciones como empíricamente infundadas y moralmente repulsivas que llevan crecientemente hacia consecuencias inhumanas.

Compartimos la advertencia que los educadores en turno deben ser educados. S6́lo la auto-actividad de las masas democráticamente organizadas puede hacer eso. El socialismo es un orden social en el que las masas deciden su propio destino en libertad.

Para mirar como es el mundo en la actualidad, tenemos que verlo de marea distinta de lo que en general se lee en los periódicos o se ve en la televisión. En realidad es más complejo y me atrevo a decir de que la ofensiva neoliberal ha pasado ya su climax. Los pueblos están en el comienzo de hacerlo retroceder.

En Alemania, hemos presenciado, y esto es mucho más que una genialidad, una reacción radical de la juventud, incluyendo a los estudiantes de secundaria, en contra del aparecimiento de la xenofobia, el racismo y el neo-fascismo. Hemos visto la maravillosa cadena de luz envolviendo probablemente a dos millones de personas.

Esto es completamente diferente a lo que pas 6 a finales de los 20 y los comienzos de los treinta. En ese tiempo los nazis conquistaron las secundarias, las universidades - la juventud - mucho antes de que conquistaran el poder político. Ahora, se va exactamente en la dirección contraria. Las masas de la juventud se están moviendo en contra de la xenofobia, el racismo y el neo-fascismo mientras los partidos políticos, los movimientos políticos están orięntándose hacia la derecha.

El ejemplo más gratificante es Brasil, donde hay una lucha de la clase trabajadora en contra de un gobierno reaccionario y corrupto (junto al aparecimiento de un partido de los trabajadores).

Hay, no obstante, un lado sombrío del paisaje mundial, que consiste en que muchos de estos tesoneros movimientos son generalmente movimientos monotemáticos y discontinuos debido la falta de perspectiva de un orden social alternativo. 


\section{La credibilided del socialismo}

Todo este desarrollo mundial significa lo que en mi movimiento llamamos la crisis mundial de credibilidad del socialismo. Los trabajadores no tienen confianza ni en el estalinismo, pos-estalinismo, maorsmo, eurocomunismo ni en la socialdemocracia.

Bajo estas circunstancias. lo que tenemos a nivel mundial es una situación en la que ninguna de las dos clases sociales fundamentales, el capital y el trabajo, en el corto y mediano plazo, podrán imponer su solución histórica a la crisis mundial. Los capitalistas no pueden por razones objetivas; porque la clase trabajadora es bastante fuerte. Es mucho más fuerte que lo era en los 30 . Pero la clase trabajadora no soluciona esta crisis mundial porque no cree en un orden social alternativo.

As1, estamos frente a una profunda crisis cuyo resultado en este momento es impredecible. Tenemos que luchar por un resultado a favor de la clase trabajadora, a favor del socialismo, a favor de la sobrevivencia fisica de la humanidad. Esta es la real opción en la actualidad. No es socialismo o barbarie sino socialismo o extinción física de la raza humana.

En esta crisis, veo tres puntos como tarea clave para todos nosotros los socialistas. En primer lugar, defender incondicionalmente todas las demandas de las masas en cualquier lugar del mundo que correspondan a sus necesidades reales como ellas las vean, sin subordinar este apoyo a ninguna prioridad de naturaleza política en este $u$ otro sector del mundo o de cualquier esquema especifico de poder. Tenemos que regresar al ejemplo de lo que el movimiento laboral hizo en su origen y durante el perfodo de su más grande crecimiento desde finales los 1880 hasta el filo de la Primera Guerra Mundial.

Los socialistas tenían dos grandes metas en ese tiempo: el día laboral de ocho horas y la franquicia universal y ellos no comenzaron por la pregunta ¿cómo vamos a hacer eso, con que forma de poder, con que forma de gobierno? No, ellos dijeron estas son necesidades objetivas de la emancipación humana y lucharemos por ellas con todos los medios posibles y necesarios y veremos que obtenemos.

En algunos parses, el día laboral de ocho horas fue conquistado por medio de huelgas generales, acciones directas extraparlamentarias de masas. En otros palses fue realizado por medio de gobiernos que podrian considerarse gobiemos de rabajadores. En otros parses fue dado por la burguesía como una concesión a un poderoso movimiento de trabajadores, tratando de prevenir que hiciera una revolución. Pero ésta no se hizo ni aquí ni allá. El hecho real fue que el dra laboral de ocho horas, como lo señalaron Marx y Engels, era un interés objetivo de la clase trabajadora y esa es la razón por la cual no se debe subordinar la lucha por 
tales demandas a ningún esquema de poder pre-establecido.

La segunda tarea de los socialistas y comunistas en el mundo actual es la educación básica socialista y la propaganda. La humanidad no puede ser salvada sin sustituir esta sociedad actual por una diferente a la que podríamos llamarla sociedad socialista. Podría llamarse una sociedad en transición hacia el comunismo, podría llamarse como Ud. quisiera, la etiqueta no haría la diferencia, pero los contenidos del socialismo deben ser especificados, tal como son aceptados por las masas. Cuando hablo de masas, hablo de cientos de millones de gentes en todo el mundo, no de pequeños grupos.

Después de las desastrosas experiencias de la social democracia, del estalinismo y el post-estalinismo, la imagen del socialismo solo puede ser una de emancipación radical con una dimensión de feminismo radical, una defensa radical del medio ambiente, una conciencia radical pacifista anti-guerra, un pluralismo político y una identificación total con los derechos humanos sin excepción.

Ahora abordo la tercera condición para solucionar la terrible crisis de credibilidad del socialismo a escala mundial. Esta es la reunificación del socialismo y la libertad. La burguesía ha cometido un error estratégico terrible al elevar el tema de los derechos humanos en contra de los socialistas de todo el mundo. Se convertirá en un bumerán que golpeará una y otra vez. Pero para que esto suceda, la reunificación del socialismo con la libertad humana debe ser completa.

A mitad de los 20, la canción tradicional del movimiento laboral italiano "Bandiera Rossa" contenía estas maravillosas palabras: "Larga vida al comunismo y a la libertad". Uno de los más grandes crímenes del estalinismo, pos-estalinismo y socialdemocracia ha sido provocar el divorcio histórico entre estos dos valores. Nosotros debemos a regresar aquello.

Mencionaré al pasar que aquí, en los Estados Unidos, a la mitad de los 20 , dos anarquistas, anticomunistas -ellos no tuvieron ninguna simpatía por el comunismo-, Sacco y Vanzetti, fueron condenados a muerte por el gobiemo burgués reaccionario. Su causa fue asumida por el Partido Comunista de los Estados Unidos y por la Internacional Comunista. El hecho de que fueran anarquistas, anti-comunistas, no hizo ninguna diferencia. Digo con orgullo que nuestro camarada James P. Cannon jugo un papel significativo al organizar la campaña mundial en favor de estos dos anarquistas. Esta es la tradición a la cual debemos regresar sin ninguna restricción.

Quienes cometan crímenes en contra de los derechos humanos bajo cualquier pretexto en cualquier país, deben ser condenados por los socialistas-comunistas del mundo. Esta es la precondición para restaurar la confianza entre las masas de nuestro movimiento. Una vez que la confianza sea restaurada adquiriremos un poder moral, un crédito moral, una fuerza moral que tiene diez veces más empuje que toda la armeria que los capitalistas controlan. 


\section{El internacionalismo revolucionario}

Espero que se vea como una imposición sobre mis amigos de la Escuela Marxista si digo unas palabras acerca de mi organización, la Cuarta Internacional, antes de terminar esta charla. Me gustaría señalar un punto.

En el New York Times de este día (febrero 21, 1993) hay un articulo sobre el referendum uruguayo rechazando la privatización. El órgano de prensa de la Cuarta Internacional, "International Wiewpoint", publicó esa información cuatro semanas antes que el Times. No porque seamos periodistas más inteligentes, ese no es el punto, o téricos más inteligentes; sino porque nosotros tenemos una real implantación en el movimiento de masas en muchos países. Los camaredas apreciaron lo que estaba sucediendo. No puedes engañarlos, ellos conocen los datos por medio de su actividad práctica.

Hace unas semanas tuvimos una reunión con nuestros lideres internacionales. En forma similar, aprendimos de nuestros amigos polacos que desputs que el parlamento reaccionario votó sobre una ley que declaraba ilegal al aborto, en un tiempo de un par de días, 1.8 millones de firmas fueron reunidas por la gente para pedir un referendum para restaurar el derecho al aborto. No quiero taminar mi charla con una nota tan positiva. Esta integración de los maxistas revolucionarios con los movimientos de masas reales de muchos parses - no en lodos los países, sería una tonteria esa pretensión- adentro y fuera de éstos, no soluciona el problema. Es justamente otra contribución. Tenemos una gran batalla para restaurar la credibilidad del comunismo-socialismo.

\section{En defensa del marxismo}

Después de ésto, quiero decir a mis amigos de la Escuela Marxista que tienen toda la razón en apoyar al marxismo y en no ceder frente a las presiones no marxistas que nos rodean por todos lados. Algunas son abiertas, otras son difusas, pero están rodeándonos por todos lados.

El marxismo es la mejor cosa que le ha sucedido al pensamiento y a la acción social en los últimos ciento cincuenta años. Los que niegan Esto, los que hacen responsable al marxismo de la contrartevolución estalinista del apoyo socialdemócrata a las guerras coloniales, o son ignorantes o mentirosos deliberados. El marxismo ha dado a la humanidad dos conquistas fundamentales que tenemos que defender, pero con la seguridad y la auto-confianza de que estamos defendiendo una buena causa.

El marxismo es la ciencia de la sociedad. Es la comprensión de una manera coherente de lo que ha estado sucediendo en los últimos doscientos años, si es que no más, sobre la base de una tremenda riqueza de información empirica y, sin ninguna duda, valiosa, incluso parcialmente valiosa, alternativa entre las cien- 
cias sociales.

No hacemos predicciones sobre el futuro. La única forma cientifica del marxismo es el marxismo abierto. Marxismo que, como el mismo Marx dijo, integra la duda constructiva. Todo permanece abierto a la reconsideración, pero sólo sobre la base de los hechos. Aquellos que hacen ésto de una manera irresponsable sin tomar en consideración los hechos; aquellos que rechazan esta tremenda herramienta para comprender la realidad del mundo no obtienen nada a cambio sino el escepticismo, la irracionalidad, la mistificación o la mitología, y no sirven a propósitos positivos.

Tan importante como el marxismo ciencia, lo es su segundo componente básico: el componente moral. El mismo Marx formuló ésto de una manera radical. Desde su juventud a través de su vida él no se separó ni por un sólo minuto de la definición que llamó el imperativo categórico. Esto es, luchar contra las condiciones en las cuales el ser humano es desposeído, alienado, explotado, oprimido o negado en su dignidad humana básica. Cualesquiera que sean los pretextos para justificar estas negaciones, debemos oponernos incondicionalmente. Comprender que no podemos ser felices si no sabemos que hemos dedicado la vida a esta defensa de los derechos humanos en cualquier lugar del mundo; la defensa de los explotados, los oprimidos, los desposeídos.

No hay una mejor manera de ser un buen ser humano en este mundo que dedicar la vida a esta gran causa. Este es el por qué el futuro está con el marxismo.

Traducción libre de Rafael Guido Béjar 